\title{
ОСОБЕННОСТИ ФИЗИОЛОГИЧЕСКИХ ПОКАЗАТЕЛЕЙ ШКОЛЬНИКОВ 7-12 ЛЕТ ПРИ ЗАНЯТИЯХ МЕНТАЛЬНОЙ АРИФМЕТИКОЙ, ВКЛЮЧАЮЩИХ ФИЗИЧЕСКИЕ УПРАЖНЕНИЯ С ПЕРЕКЛЮЧЕНИЕМ ВНИМАНИЯ
}

\author{
В. В. Горелик ${ }^{1 凶}$, С. Н. Филиппова², Т. П. Кнышева ${ }^{3}$
}

\author{
'Кафедра адаптивной физической культуры, спорта и туризма, \\ Институт физической культуры и спорта, Тольяттинский государственный университет, Тольятти \\ 2Кафедра адаптивной физической культуры и медико-биологических дисциплин, \\ Институт естествознания и спортивных технологий, Московский городской педагогический университет, Москва \\ ЦЦентр интеллектуального развития «Эврика», Тольятти
}

\begin{abstract}
В условиях современного образования школьники подвергаются большим учебным нагрузкам. В связи с этим целью работы было изучить влияние физических упражнений с переключением внимания, используемых на занятиях ментальной арифметикой, на показатели сердечного ритма, адаптационные возможности, стрессоустойчивость, характеристики высших психических функций и условно-реслекторной деятельности детей. При обследовании 124 школьников 7-9 лет и 10-12 лет использовали метод педагогического эксперимента, включающего констатирующий, формирующий и контрольный этапы, а также ряд психологических методик: диагностику кратковременной ассоциативной и образной памяти; корректурную пробу Бурдона; поиск логических решений; определение моторной одаренности. Для диагностики функционального состояния сердечно-сосудистой системы и других показателей физиологического состояния использовали программно-аппаратный комплекс «Варикард 2.51». На констатирующем этапе у школьников выявлены половозрастные различия высших психических функций. У девочек 7-9 лет показатели памяти, внимания, мышления были выше на 20-40\%, чем у мальчиков этого возраста. У мальчиков 10-12 лет отмечался рост показателей высших психических функций по сравнению с девочками того же возраста на 10-30\%. На формирующем этапе показано оптимизирующее воздействие двигательных упражнений с переключением внимания на скорость переработки информации и продуктивность запоминания, показатели которых увеличивались у детей обоего пола в 1,5-2 раза (7-9 лет) и в 1,2-1,5 раза (10-12 лет). Сделан вывод, что включение физических упражнений с переключением внимания повышает эффективность обучения ментальному счету.
\end{abstract}

Ключевые слова: школьники младших классов, когнитивная сфера, познавательная активность, функциональная активность сердечно-сосудистой системы, возрастная психофизиология, ментальная арифметика

Для корреспонденции: Виктор Владимирович Горелик ул. Белорусская, д. 14, г. Тольятти, 445020; lecgoy@list.ru

Статья получена: 18.05.2018 Статья принята к печати: 06.10.2018

DOI: $10.24075 /$ vrgmu.2018.057

\section{PHYSIOLOGICAL INDICATORS OF SCHOOLCHILDREN OF 7-12 YEARS OF AGE PECULIAR TO MENTAL ARITHMETIC SESSIONS COMBINED WITH ATTENTION SWITCHING PHYSICAL EXERCISES}

Gorelik W'1 ${ }^{1}$, Filippova SN², Knysheva TP³

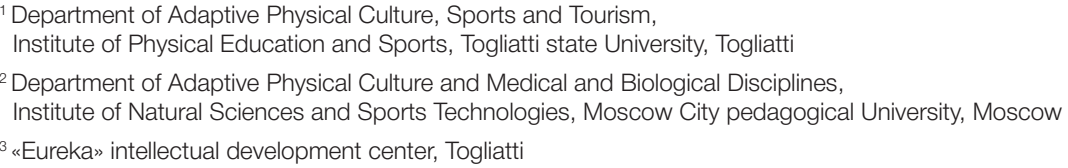

Present day education routines subject schoolchildren to considerable loads associated with studying. This research effort aimed to study the effect attention switching physical exercises (the type peculiar to the mental arithmetic curricula) have on heart rate, adaptation abilities, stress resistance, higher mental functions and conditioned reflex activity of children. Examining 124 schoolchildren aged 7-9 and 10-12 years, we applied the pedagogical experiment method that includes benchmarking, formation and control stages, as well as a number of psychological methods: short-term, associative and image memory diagnostics; Bourdon-Wiersma test; search for logical solutions; evaluation of motor skills. Varicard 2.51 was used to assess functions of the cardiovascular system and other physiological state indicators. At the benchmarking stage, we discovered the differences in higher mental functions conditioned by age and gender. Girls aged 7-9 had their memory, attention, ideation indicators 20-40\% higher than boys of the same age. Boys aged 10-12 had their higher mental functions developed 10-30\% better than girls of the same age. At the formation stage, we registered the optimizing effect attention switching physical exercises have on information processing speed and memorizing effectiveness: corresponding indicators increased 1.5-2 times (7-9 y.o., both genders) and 1.2-1.5 times (10-12 y.o., both genders), accordingly. It was concluded that adding the attention switching physical exercises to mental arithmetic curricula makes training sessions more effective.

Keywords: schoolchildren, cognitive sphere, cognitive activity, functional activity of CVS, age psychology, mental arithmetic

Correspondence should be addressed: Victor V. Gorelik

Belorusskaya 14, Togliatti, 445020; lecgoy@list.ru

Received: 18.05.2018 Accepted: 06.10.2018

DOI: 10.24075/brsmu.2018.057 
В образовательном пространстве школы современные учащиеся, находясь в условиях интенсификации учебной деятельности, постоянно сталкиваются с возрастающими информационными нагрузками, в том числе с применением сверхнормативных обучающих технологий в системе дополнительного образования. В связи с этим требуется усиленный контроль состояния адаптации и здоровья детей в процессе школьного обучения [1-5]. В качестве интегрального индикатора адаптации в современной психофизиологии широко используются показатели вегетативного баланса при различных видах деятельности, в том числе в учебном процессе.

Установлено, что под влиянием психофизических нагрузок, оптимальное соотношение симпатического и парасимпатического звеньев регуляции может нарушаться в пользу преобладания симпатикотонии, что свидетельствует о дисбалансе реципрокных регуляторных влияний вегетативной нервной системы (ВНС) на кардиальную систему ребенка. В таких условиях наблюдается выраженное напряжение компенсаторных механизмов сердечно-сосудистой системы (ССС) детского организма, связанное с особенностями его адаптации к физическим и умственным нагрузкам [3, 6, 8, 9]. При умственном и физическом переутомлении, эмоциональном стрессе повышаются психоэмоциональное напряжение и уязвимость организма ребенка, что приводит к нарастанию процессов психосизической и социальной дезадаптации $[2,4,7,8]$.

Преобладание (доминирование) функциональной активности одного из отделов ВНС свойственно значительному числу детей, особенно в условиях чрезмерных средовых нагрузок, превышающих адаптационные возможности ребенка $[4,5,9,10]$. Изменение регуляторных влияний высшей нервной деятельности и высших психических функций (ВПФ), зависящих от состояния центральной нервной системы (ЦНС), головного мозга и его коры, приводит к изменению скорости условнорефлекторных реакций, нарушению взаимодействия между первой и второй сигнальными системами, психосоматическим и поведенческим отклонениям и др. Детей с такими отклонениями относят к группе условно здоровых, но имеющих значительное напряжение процессов адаптации (преморбидное, донозологическое состояние), которое может приводить к срыву, в первую очередь, регуляторных звеньев физиологических процессов организма ребенка, снижению умственной и физической работоспособности детей, отставанию в учебной деятельности [1, 4, 6, 9, 11-14].

В процессе онтогенеза ребенка происходят динамические перестройки взаимодействия между функциональными системами организма, скорость которых растет в связи с явлениями акселерации. При этом в детском организме формируются механизмы адаптации к физическим и умственным нагрузкам, важную роль в их становлении играет перестройка вегетативной регуляции функций организма $[4,8]$.

Понимание возрастных особенностей адаптациогенеза детей по интегративным психофизиологическим характеристикам, изменяющимся под влиянием учебной деятельности, позволит создать для школьников оптимальную образовательную среду и систему занятий, психолого-педагогическое сопровождение учебного процесса. Такие меры диктуются основным противоречием современного образования: при ускоренном возрастании умственных нагрузок у школьников прогрессирует десицит двигательной активности, вызванный изменением образа жизни современных детей в условиях урбанизированной среды [4, 7, 15-17]. Однако многие интегративные механизмы онтогенеза и возрастной адаптации под влиянием учебных и средовых нагрузок у современных школьников остаются недостаточно исследованными.

Целью работы было изучение влияния факторов образовательной среды (ментального счета, двигательных упражнений и переключения внимания) на особенности развития физиологических функций и когнитивных процессов школьников в наиболее сенситивные возрастные периоды 7-9 и 10-12 лет в условиях высоких учебных нагрузок. В задачи входило: оценить психофизическое развитие и его изменения у младших школьников под влиянием физических упражнений с включением заданий на переключение внимания (счет, арифметические действия); выявить различия познавательной активности и физиологических функций в зависимости от фактора пола у детей 7-12 лет; изучить влияние физических упражнений на когнитивные процессы учащихся в процессе занятий ментальной арифметикой с учетом фризиологических особенностей младших школьников.

\section{ПАЦИЕНТЫ И МЕТОДЫ}

\section{Характеристика обследованных школьников}

В исследовании приняли участие 124 школьника, обучавшихся в Центре интеллектуального развития «Эврика» г. Тольятти в период с октября 2017 по май 2018 г. Из которых 30 мальчиков и 32 девочки были в возрасте 7-9 лет; 30 мальчиков и 32 девочки в возрасте 10-12 лет. Каждую половозрастную категорию разделили на: основную группу (ОГ) и группу сравнения (ГС). Критерием деления на ОГ и ГС было относительное равенство исходных психофизиологических и когнитивных показателей.

\section{Этическая экспертиза}

Исследование одобрено локальным этическим комитетом Тольяттинского государственного университета (протокол № 1 от 29 августа 2017 г). Получено информированное согласие от родителей на участие школьников в эксперименте.

Критерии включения в эксперимент: возраст детей 7-12 лет; отсутствие медицинских противопоказаний к учебной деятельности и физической нагрузке. Критерии исключения: острые инфекционные заболевания и иные медицинские противопоказания $\mathrm{k}$ учебным занятиям и фризическим упражнениям. Возрастной период 7-9 лет характеризуется интенсивным развитием мозговых структур, обеспечивающих познавательную деятельность $[13,14,18,19]$. Период 10-12 лет характеризуется дальнейшим развитием основных структур мозга, ответственных за когнитивные процессы, и завершением формирования индивидуального профиля латеральной специализации функций полушарий мозга [11, 20].

\section{Программа ментального счета}

Обучение ментальному счету осуществляли в обеих группах в течение 6 месяцев по 2 раза в неделю, продолжительность каждого занятия составляла 45 мин. Дети осваивали ментальный счет с помощью специальных арифметических счетов - абакуса и проводили вычисления в уме. В соответствии с индивидуальными особенностями 
и текущим психофизическим состоянием все участники эксперимента по-разному переносили умственные нагрузки. Для оптимизации психофизических показателей в ОГ были включены двигательные упражнения (ДУ) с переключением внимания (ПВ) в отличие от занятий в ГС.

\section{Программа двигательных упражнений с переключением внимания}

В процессе обучения ментальному счету физкультурнооздоровительные упражнения с ПВ вводили в начале, в середине и в конце занятия. Дети выполняли следующие ДУ с ПВ: 1) игры с мячом; 2) счет с мячом; 3) прыжки со счетом; 4) стояние на балансировочной доске в комбинации со счетом и ответами на вопросы. Во время выполнения ДУ с ПВ ребенок лучше концентрируется у него активизируется максимальное количество мышц, формирующих осанку, укрепляющих сухожилия и связки ног, ловкость и координацию движений, развитие восприятия и сенсомоторной координации Занятия ментальной арифметикой и ДУ с ПВ (счетом, арифметическими действиями) стимулируют психомоторную активность и направлены на увеличение ментальной активности, общего объема и разнообразия движений, развитие ловкости, гибкости, быстроты, координационных способностей.

\section{Метод педагогического эксперимента}

Определение показателей познавательной активности осуществляли в процессе проведения трех этапов педагогического эксперимента:

1) констатирующий этап (октябрь 2017 г.): определяли исходные показатели функционального состояния ССС, адаптации детей и уровень развития познавательных процессов;

2) формирующий этап (декабрь 2017 г. - апрель 2018 г.): когнитивные задания и средства физической культуры использовали для развития моторики и психических процессов;

3) контрольный этап (май 2018 г.): определяли итоговые показатели после воздействия на детей формирующих упражнений, стимулирующих умственную и физическую активность.

\section{Психодиагностические методы}

В психодиагностическую программу вошли следующие психологические методики:

1) диагностика кратковременной памяти (запоминание 10 слов);

2) диагностика ассоциативной памяти (10 парных ассоциаций);

3) диагностика образной памяти (16 образов);

4) корректурная проба Бурдона;

5) поиск аналогий и логических решений;

6) определение моторной одаренности у детей и подростков 7-12 лет по метрической шкале [21-23].

ДУ с ПВ включали в занятия только в ОГ.

\section{Метод диагностики функциональных показателей организма}

Для определения функционального состояния ССС детей использовали программно-аппаратный комплекс
(АПК) «Варикард 2.51» (Институт внедрения новых медицинских технологий «Рамена»; Россия). Методом анализа вариабельности сердечного ритма исследовали все основные показатели, в том числе:

- вегетативную регуляцию кровообращения с оценкой степени напряжения регуляторных систем организма;

- вегетативную регуляцию ритма сердца (исходный уровень вегетативной регуляции, вегетативную реактивность, вегетативное обеспечение деятельности);

- функциональное состояние организма и его изменений на основе определения параметра вегетативного баланса и нейрогуморальной регуляции.

На основе оценки текущего функционального состояния организма, выраженности его адаптационных ответов и состояния регуляторных систем разработаны прогностические заключения и рекомендации, которые использовались в данном исследовании и были предложены в учебном процессе [24].

\section{Методы математической статистики}

Обработку результатов исследования проводили с использованием методов математической статистики: одновыборочного критерия оценки нормальности распределения Колмогорова-Смирнова и параметрического $t$-критерия Стьюдента. Статистическую значимость наличия различий определяли на уровне $p<0,05$.

Применение одновыборочного критерия КолмогороваСмирнова к полученным данным выявило распределение исследуемых переменных в границах нормальности, что позволило в дальнейшем использовать параметрический t-критерий Стьюдента для связных и несвязных выборок.

Результаты экспериментального исследования обрабатывали с помощью программы SPSS 17.0 for Windows.

\section{РЕЗУЛЬТАТЫ ИССЛЕДОВАНИЯ}

Рассматривая функциональные показатели развития детей на констатирующем этапе, мы наблюдали близкие по величине показатели функционального состояния регуляторных систем в ОГ и ГС. Известно, что даже небольшие изменения вегетативного баланса значительно влияют на состояние здоровья обучающихся детей, это приводит к снижению стрессоустойчивости и адаптации к действующим в процессе учебной деятельности физическим и умственным нагрузкам.

У детей младшего школьного возраста наблюдается колебательный характер межсистемных и внутрисистемных взаимоотношений между психоэмоциональными, вегетативными и гормонально-метаболическими механизмами. Это приводит к нестабильности и снижению функциональных и приспособительных возможностей организма в результате постоянного функционального напряжения регуляторных систем под влиянием учебных нагрузок $[4,6,8]$.

Для исследования вегетативного баланса было проведено определение функционального состояния ССС методом вариабельности сердечного ритма.

В начале исследования отмечалось увеличение стрессиндекса Si (отражает степень преобладания активности центральных механизмов регуляции над автономными). В ОГ этот показатель составлял 298 усл. ед., в ГС - 486 усл. ед., что свидетельствовало о высокой активности регуляторных систем и пониженных функциональных резервах организма. Эти результаты в ОГ и ГС указывали на то, что вследствие возрастания учебных нагрузок происходит 
умственное и физическое утомление детей, которое приводит $\mathrm{k}$ нарушению баланса симпатического и парасимпатического отделов нервной системы. Так как морфофункциональные структуры ЦНС еще не достигли своей зрелости в исследуемых группах детей 7-12 лет, сила и уравновешенность нервных процессов относительно невелики, что может приводить к быстрой истощаемости клеток коры головного мозга, утомлению и снижению умственной работоспособности. При наступлении умственного и физического утомления необходимо своевременное переключение детей на другой вид деятельности.

В связи с этим в занятия по обучению ментальному счету ввели физкультурно-оздоровительные упражнения с переключением внимания в начале, середине и конце занятия.

Также на констатирующем и контрольном этапах педагогического эксперимента были исследованы показатели продуктивности запоминания, концентрации и переключаемости внимания, функций мышления и моторной одаренности у мальчиков и девочек 7-9 и 1012 лет. Проведено сравнение результатов в возрастных группах (табл. 1-4):

- 7-9 лет: ОГ (15 мальчиков, 16 девочек) и ГС (15 мальчиков, 16 девочек);

- 10-12 лет: ОГ (15 мальчиков, 16 девочек) и ГС (15 мальчиков, 16 девочек).

Результаты диагностики памяти, внимания и мышления на констатирующем этапе исследования показали, что показатели кратковременной, ассоциативной и образной памяти, концентрации и переключаемости внимания у девочек 7-9 лет имеют большие значения (на 20-40\%), чем у мальчиков этой же возрастной группы (табл. 1, 2). Эти зависящие от фактора пола особенности связаны с опережающим онтогенетическим развитием девочек по сравнению с мальчиками $[18,19]$. У девочек на 0,5-1 год раньше наступает первый ростовой скачок, и развитие психологических показателей, синхронизированное с морфофункциональным формированием организма, происходит опережающими темпами.
В возрасте 10-12 лет продуктивность запоминания, концентрация и переключаемость внимания, а также эффективность решения логических задач у мальчиков возрастают (на 10-30\%) по сравнению с девочками (табл. 3, 4) за счет зависящих от фактора пола особенностей профилей латеральной организации полушарий головного мозга $[17,18,20]$. У мальчиков завершается формирование профилей латеральной организации с преобладанием активности левого полушария, в то время как у девочек отмечается эквипотенциальный вариант активности полушарий.

Это детерминированное половозрастными факторами повышение психологических показателей умственной деятельности свидетельствует о возрастании морфофункциональной готовности мозга и психических процессов в решении пространственно-временных задач $[5,20]$.

Результаты исследований двух возрастных групп детей показали также, что двигательные возможности девочек превышают таковые у мальчиков в связи с опережающим на этом этапе онтогенеза развитием различных звеньев двигательного анализатора, включая его высшие корковые отделы.

Рассматривая функциональные показатели развития детей на констатирующем этапе, мы наблюдали близкие по величине показатели функционального состояния регуляторных систем в ОГ и ГС. Известно, что даже небольшие изменения вегетативного баланса значительно влияют на состояние здоровья обучающихся детей, что снижает стрессоустойчивость, адаптацию к действующим физическим и умственным нагрузкам в учебном процессе $[2,6,9,10]$. Для исследования этих особенностей было проведено определение функционального состояния ССС методом измерения вариабельности сердечного ритма (табл. 5-7).

После завершения ФЭ педагогического эксперимента повторно было проведено исследование регуляторных систем организма, результаты которого свидетельствуют о том, что в ОГ детей при использовании физкультурно-

Таблица 1. Сравнение показателей памяти, внимания, мышления и моторной одаренности (в баллах) у мальчиков 7-9 лет в ОГ и ГС

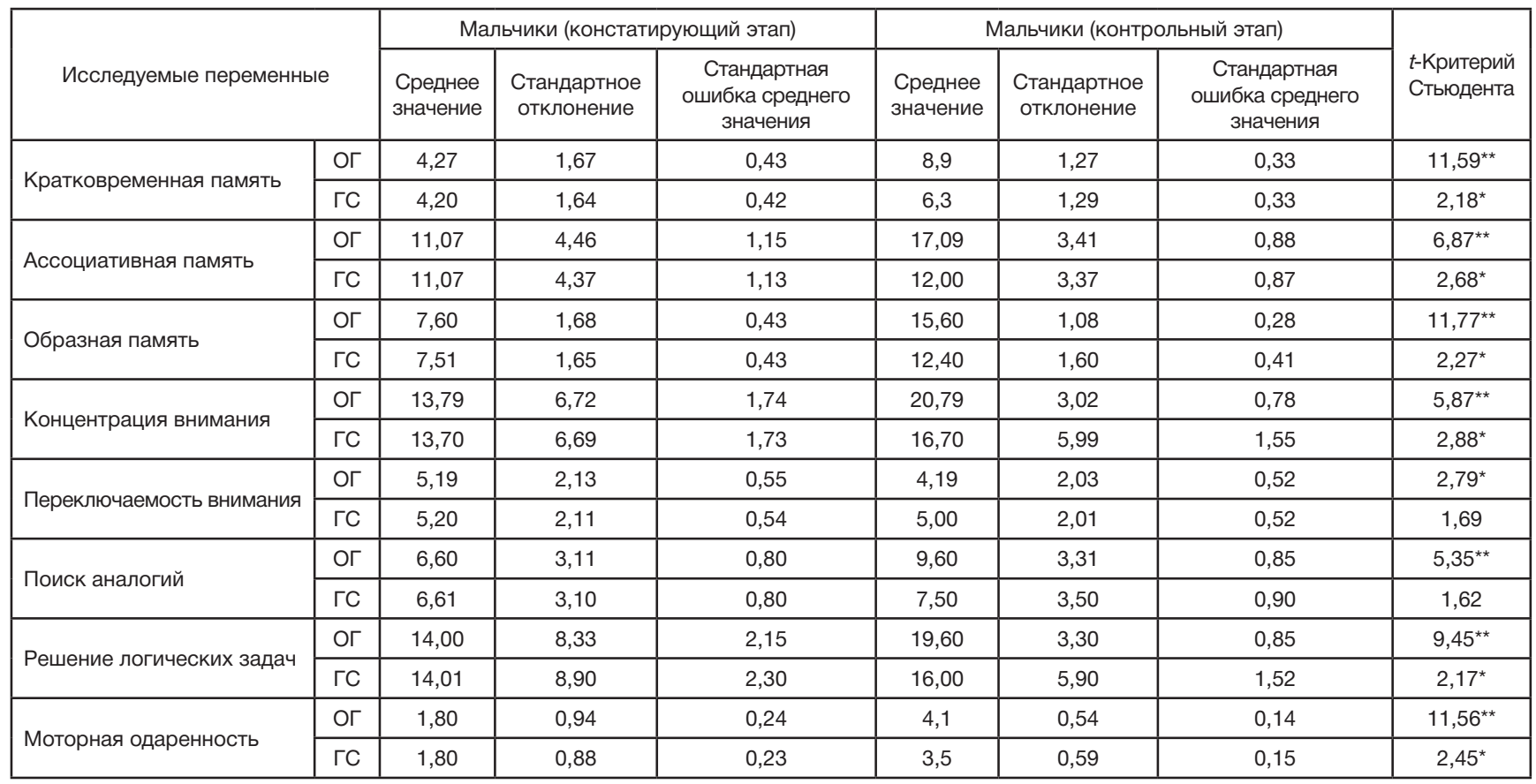

Примечание: * - уровень значимости $p \leq 0,05 ;{ }^{*}$ - уровень значимости $p \leq 0,01$. 
оздоровительных занятий и правильной организации режима дня происходит улучшение функционального состояния организма.

В табл. 5 представлены данные измерений показателей сердечного ритма в ОГ и ГС на завершающем контрольном этапе педагогического эксперимента.

Данные табл. 5 свидетельствуют о стабилизации функциональных процессов, значения Si (индекса напряжения регуляторных систем) и частоты сердечных сокращений у школьников ОГ близки к физиологической норме. Системы регуляции работают в нормальном режиме, организм оптимально выходит из стрессовых ситуаций, системы организма стабильны, что свидетельствует о правильном соотношении умственных и физических нагрузок и организации физкультурно-оздоровительного режима занятий.

В ГС в конце исследования наблюдаются высокий Si, тахикардия, высокая активность регуляторных систем и сниженные функциональные резервы организма (табл. 5). Это состояние сопровождается перенапряжением

таблица 2. Сравнение показателей памяти, внимания, мышления и моторной одаренности (в баллах) у девочек 7-9 лет в ОГ и ГС

\begin{tabular}{|c|c|c|c|c|c|c|c|c|}
\hline \multirow{2}{*}{\multicolumn{2}{|c|}{ Исследуемые переменные }} & \multicolumn{3}{|c|}{$\begin{array}{c}\text { Девочки } \\
\text { (констатирующий этап) }\end{array}$} & \multicolumn{3}{|c|}{$\begin{array}{c}\text { Девочки } \\
\text { (контрольный этап) }\end{array}$} & \multirow{3}{*}{$\begin{array}{c}t \text {-Критерий } \\
\text { Стьюдента } \\
11,90^{\star *} \\
\end{array}$} \\
\hline & & \multirow{2}{*}{$\begin{array}{c}\text { Среднее } \\
\text { значение } \\
5,27\end{array}$} & \multirow{2}{*}{$\begin{array}{c}\begin{array}{c}\text { Стандартное } \\
\text { отклонение }\end{array} \\
1,27\end{array}$} & \multirow{2}{*}{$\begin{array}{c}\begin{array}{c}\text { Стандартная } \\
\text { ошибка среднего } \\
\text { значения }\end{array} \\
0,32 \\
\end{array}$} & \multirow{2}{*}{$\begin{array}{c}\text { Среднее } \\
\text { значение } \\
9,51\end{array}$} & \multirow{2}{*}{$\begin{array}{c}\text { Стандартное } \\
\text { отклонение }\end{array}$} & \multirow{2}{*}{$\begin{array}{c}\begin{array}{c}\text { Стандартная } \\
\text { ошибка среднего } \\
\text { значения }\end{array} \\
0,41 \\
\end{array}$} & \\
\hline & ОГ & & & & & & & \\
\hline Кратковременная память & $\Gamma \mathrm{C}$ & 5,20 & 1,09 & 0,27 & 7,20 & 1,67 & 0,42 & $2,21^{*}$ \\
\hline \multirow{2}{*}{ Ассоциативная память } & ог & 15,00 & 3,85 & 0,96 & 19,00 & 2,85 & 0,71 & $4,61^{* *}$ \\
\hline & $\Gamma \mathrm{C}$ & 14,01 & 2,62 & 0,66 & 14,01 & 3,60 & 0,90 & 2,05 \\
\hline \multirow{2}{*}{ Образная память } & ог & 10,82 & 2,75 & 0,69 & 15,12 & 2,15 & 0,54 & $5,9^{* *}$ \\
\hline & $\Gamma \mathrm{C}$ & 10,90 & 2,64 & 0,66 & 11,00 & 2,34 & 0,59 & $2,34^{*}$ \\
\hline \multirow{2}{*}{ Концентрация внимания } & ог & 20,92 & 6,83 & 1,71 & 26,92 & 3,43 & 0,86 & $3,11^{\star \star}$ \\
\hline & $\Gamma \mathrm{C}$ & 20,80 & 6,87 & 1,72 & 24,80 & 5,87 & 1,47 & $2,52^{*}$ \\
\hline \multirow{2}{*}{ Переключаемость внимания } & ог & 4,75 & 2,39 & 0,60 & 3,60 & 1,39 & 0,35 & $2,71^{*}$ \\
\hline & $\Gamma \mathrm{C}$ & 4,61 & 2,40 & 0,60 & 4,10 & 1,40 & 0,35 & 2,11 \\
\hline \multirow{2}{*}{ Поиск аналогий } & ог & 8,73 & 2,61 & 0,65 & 11,5 & 2,41 & 0,60 & $4,03^{* \star}$ \\
\hline & $\Gamma \mathrm{C}$ & 8,62 & 2,51 & 0,63 & 8,70 & 2,50 & 0,63 & 1,86 \\
\hline \multirow{2}{*}{ Решение логических задач } & ог & 18,82 & 6,28 & 1,57 & 26,80 & 3,28 & 0,82 & $7,09^{* \star}$ \\
\hline & $\Gamma \mathrm{C}$ & 18,91 & 5,47 & 1,37 & 22,90 & 5,75 & 1,44 & 2,02 \\
\hline \multirow{2}{*}{ Моторная одаренность } & ог & 2,82 & 0,75 & 0,19 & 3,40 & 4,50 & 1,13 & $8,91^{\star \star}$ \\
\hline & $\Gamma \mathrm{C}$ & 2,81 & 0,75 & 0,19 & 2,91 & 4,75 & 1,19 & $2,71^{*}$ \\
\hline
\end{tabular}

Примечание: * - уровень значимости $p \leq 0,05 ;{ }^{*}$ - уровень значимости $p \leq 0,01$.

Таблица 3. Сравнение показателей памяти, внимания, мышления и моторной одаренности (в баллах) у мальчиков 10-12 лет в ОГ и ГС

\begin{tabular}{|c|c|c|c|c|c|c|c|c|}
\hline \multirow{2}{*}{\multicolumn{2}{|c|}{ Исследуемые переменные }} & \multicolumn{3}{|c|}{$\begin{array}{c}\text { Мальчики } \\
\text { (констатирующий этап) }\end{array}$} & \multicolumn{3}{|c|}{$\begin{array}{c}\text { Мальчики } \\
\text { (контрольный этап) }\end{array}$} & \multirow{3}{*}{$\begin{array}{r}t \text {-Критерий } \\
\text { Стьюдента } \\
6,59^{\star \star}\end{array}$} \\
\hline & & \multirow{2}{*}{$\begin{array}{c}\text { Среднее } \\
\text { значение } \\
6,63\end{array}$} & \multirow{2}{*}{$\begin{array}{c}\text { Стандартное } \\
\text { отклонение }\end{array}$} & \multirow{2}{*}{$\begin{array}{c}\text { Стандартная } \\
\text { ошибка среднего } \\
\text { значения }\end{array}$} & \multirow{2}{*}{$\begin{array}{c}\text { Среднее } \\
\text { значение }\end{array}$} & \multirow{2}{*}{$\begin{array}{c}\begin{array}{c}\text { Стандартное } \\
\text { отклонение }\end{array} \\
0,53\end{array}$} & \multirow{2}{*}{$\begin{array}{c}\text { Стандартная } \\
\text { ошибка среднего } \\
\text { значения }\end{array}$} & \\
\hline 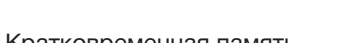 & ОГ & & & & & & & \\
\hline 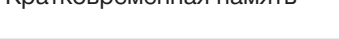 & ГC & 6,50 & 1,53 & 0,40 & 7,60 & 0,89 & 0,23 & 2,13 \\
\hline \multirow{2}{*}{ Ассоциативная память } & ОГ & 16,13 & 1,73 & 0,45 & 19,40 & 0,73 & 0,19 & $4,87^{\star \star}$ \\
\hline & ГС & 15,08 & 1,74 & 0,45 & 15,09 & 0,84 & 0,22 & 1,96 \\
\hline \multirow{2}{*}{ Образная память } & Ог & 10,38 & 2,45 & 0,63 & 15,40 & 0,74 & 0,19 & $7,17^{\star \star}$ \\
\hline & ГС & 10,30 & 2,74 & 0,71 & 13,30 & 1,02 & 0,26 & $2,29^{*}$ \\
\hline \multirow{2}{*}{ Концентрация внимания } & ОГ & 27,25 & 7,36 & 1,90 & 34,00 & 4,31 & 1,11 & $4,84^{\star \star}$ \\
\hline & ГC & 27,40 & 6,89 & 1,78 & 29,40 & 6,43 & 1,66 & $2,18^{*}$ \\
\hline \multirow{2}{*}{ Переключаемость внимания } & Ог & 5,60 & 1,80 & 0,46 & 3,40 & 0,97 & 0,25 & $4,12^{* \star}$ \\
\hline & ГC & 5,80 & 1,94 & 0,50 & 4,20 & 1,14 & 0,29 & $2,69^{*}$ \\
\hline \multirow{2}{*}{ Поиск аналогий } & ОГ & 9,25 & 1,98 & 0,51 & 12,00 & 0,04 & 0,01 & $2,99^{* *}$ \\
\hline & ГС & 9,40 & 1,90 & 0,49 & 10,5 & 1,01 & 0,26 & $2,62^{*}$ \\
\hline \multirow{2}{*}{ Решение логических задач } & ОГ & 23,75 & 5,57 & 1,44 & 28,90 & 1,80 & 0,46 & $3,44^{\star *}$ \\
\hline & ГС & 23,88 & 5,81 & 1,50 & 24,60 & 2,09 & 0,54 & $2,19^{*}$ \\
\hline \multirow{2}{*}{ Моторная одаренность } & ОГ & 2,25 & 0,71 & 0,18 & 4,10 & 0,14 & 0,04 & $5,71^{* *}$ \\
\hline & ГC & 2,30 & 0,65 & 0,17 & 3,80 & 0,36 & 0,09 & $2,49^{\star}$ \\
\hline
\end{tabular}

Примечание: * - уровень значимости $p \leq 0,05 ;{ }^{*}$ - уровень значимости $p \leq 0,01$. 
регуляторных механизмов. Длительное перенапряжение в результате учебного стресса может привести к срыву физиологической адаптации и развитию патогенной цепи: дезадаптация - предболезнь - развитие заболеваний - хронизация патологий. В связи с этим необходима правильная организация режима дня, рациональный подбор умственных и физических нагрузок и своевременное применение двигательной активности, что подтверждается данными табл. 6, 7 и рис. 1, 2.

После завершения ФЭ педагогического эксперимента было проведено повторное исследование регуляторных систем организма. Его результаты свидетельствуют о том, что в ОГ включение в структуру занятий ментальной арифметикой физкультурно-оздоровительных упражнений привело к росту двигательных нагрузок и оптимизации двигательного режима школьников. Поэтому в ОГ (рис. 1; табл. 6,) в отличие от ГС (рис. 2; табл. 2,) наблюдается положительная динамика функционального состояния детей, о чем свидетельствует улучшение соответствующих показателей. Важно отметить снижение в 1,8 раза Si в ОГ под влиянием ДУ с ПВ. Эти результаты подтверждаются данными, представленными на рис. 3, 4.

Получены различия функциионального класса школьников в ОГ и ГС в конце исследования. Локализация детей в
ОГ относится ко второму функциональному классу, что свидетельствует о фризиологической норме систем, обеспечивающих жизнедеятельность растущего организма. Это подтверждает необходимость смены видов деятельности при занятиях ментальной арифметикой с использованием дополняющих их ДУ с ПВ. Смена когнитивных и физических видов деятельности способствует: 1) активации ЦНС; 2) предупреждению монотонии; 3) переключению внимания и снижению утомляющего воздействие учебной нагрузки (рис. 3).

Локализация школьников ГС относится к шестому функциональному классу, что свидетельствует о перенапряжении систем регуляции организма детей (рис. 4). В этом случае важно обратить внимание на смену деятельности во время учебных занятий. Это будет способствовать профилактике переутомления и истощения адаптационных резервов организма и тем самым сохранению здоровья школьников в условиях роста учебных нагрузок.

Таким образом, проведенные исследования показали эффективность применения комплекса методов ментальной арифметики с ДУ, включающими ПВ, для повышения умственной продуктивности и психомоторных возможностей младших школьников.

Таблица 4. Сравнение показателей памяти, внимания, мышления и моторной одаренности (в баллах) у девочек 10-12 лет в ОГ и ГС

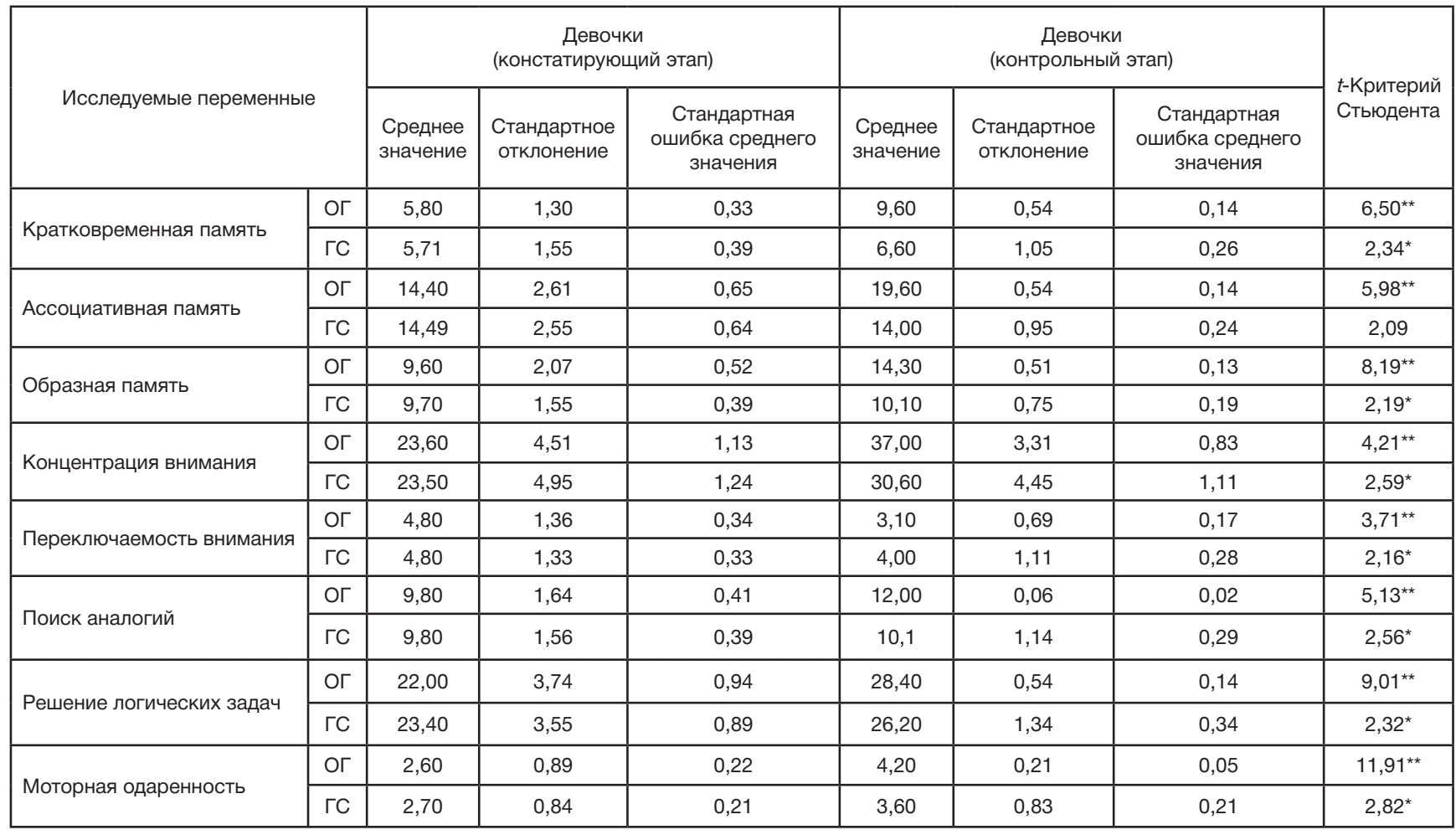

Примечание: * - уровень значимости $p \leq 0,05 ;{ }^{* *}-$ уровень значимости $p \leq 0,01$.

Таблица 5. Основные показатели сердечного ритма на контрольном этапе педагогического эксперимента в ОГ и ГС

\begin{tabular}{|c|c|c|c|}
\hline Наименование & ОГ & ГC & Норма \\
\hline Частота пульса (HR), уд./мин & 71 & $92^{\star \star}$ & $55-80$ \\
\hline Среднее квадр. отклонение (SDNM), мс & 55,8 & 51,4 & $30-100$ \\
\hline Коэффициент вариации (VC), \% & 6,6 & 7,9 & $3-12$ \\
\hline Стресс-индекс (SI), усл. ед. & 114 & $227^{\star \star}$ & $50-150$ \\
\hline Индекс централизации (/C), усл. ед. & $1,3^{\star \star}$ & $1,3^{\star *}$ & $2-8$ \\
\hline Индекс нетипичности (НТИ), усл. ед. & 2 & $6^{*}$ & $1-3$ \\
\hline
\end{tabular}

Примечание: * - уровень значимости $p \leq 0,05 ;{ }^{* *}-$ уровень значимости $p \leq 0,01$. 


\section{ОБСУЖДЕНИЕ РЕЗУЛЬТАТОВ}

Изучением физиологической адаптации детского организма к учебной деятельности занимаются многие исследователи, такие как Н. И. Шлык, Р. М. Баевский, Е. Д. Синяк, Д. Л. Сонькин и др. Особенность их работ заключается В обосновании технологии подбора адекватных двигательных нагрузок, как в тренировочном процессе, так и при занятии физической культурой с учетом физических возможностей обучающихся. В данном исследовании мы также учитывали психофизические показатели, позволяющие отнести учащихся к определенному функциональному классу. Но при работе с детьми важно использовать их высокий игровой потенциал [25], поэтому на занятиях ментальной арифметикой мы применяли ДУ с ПВ, что позволяло проводить занятия в более увлекательной форме.

В проведенном исследовании за счет включения ДУ с ПВ в занятия ментальной арифметикой произошла положительная динамика ВПФ младших школьников: возрастали показатели различных видов произвольной памяти (кратковременной, ассоциативной, образной), произвольного внимания, функций мышления и моторной одаренности. Можно предположить, что активизация ВПФ достигается благодаря профилактике монотонии, оптимизации баланса процессов возбуждения и торможения в коре головного мозга.

Результаты диагностики памяти, внимания и моторной одаренности показывают их улучшение в 1,5-2 раза после включения в занятия ментальной арифметикой двигательного компонента. Рост функциональных показателей под влиянием занятий ДУ с ПВ свидетельствует об их

Таблица 6. Показатели состояния регуляторных систем на контрольном этапе педагогического эксперимента в ОГ

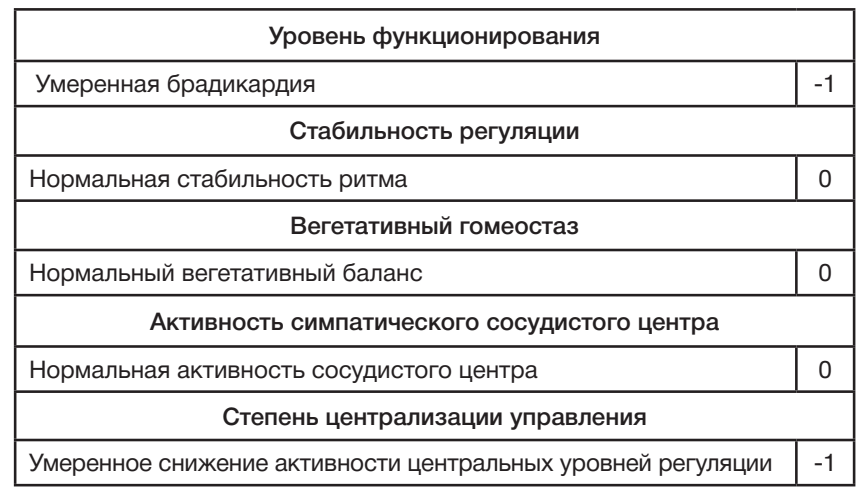

$\%$

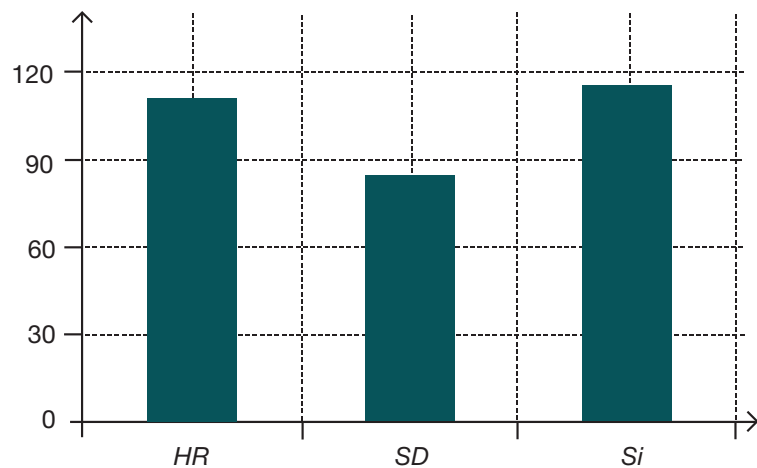

Рис. 1. Основные показатели ритма сердца на контрольном этапе педагогического эксперимента в ОГ: HR - частота пульса, уд./мин; SD среднее квадратичное отклонение, мс; Si - стресс-индекс, усл. ед. эфффективности для психомоторного развития младших школьников. Сравнение результатов констатирующего и контрольного этапов педагогического эксперимента выявило статистически значимые различия (при $p \leq 0,05)$ в основной группе школьников по всем рассмотренным параметрам.

Комплексное применение когнитивных и физических упражнений привело к профилактике утомления и оказало восстановительное и нормализующее воздействие на регуляторные системы организма. Полученные результаты свидетельствуют о том, что у школьников ОГ при использовании физкультурно-оздоровительных занятий и правильной организации режима активности и отдыха происходит улучшение функционального состояния организма. Ряд авторов отмечают, что профилактика переутомления в детском возрасте очень важна и позволяет в перспективе улучшить состояние здоровья и учебную успеваемость детей, поддерживать оптимальный уровень функционирования у них ЦНС и ВНС, обеспечивающий адекватную деятельность систем и организма в целом при действии учебных нагрузок [2-4, 8]. При нормализации функционального состояния исследователи отмечают снижение у младших школьников рисков школьной дезадаптации.

При исследовании причин неоднородности и неустойчивости нейрогуморальной регуляции сердечного ритма у детей вследствие конституционно-генетического дисбаланса созревания ВНС в онтогенезе установлено, что механизмы приспособительных реакций наилучшим образом стабилизируются при соответствующей организации двигательной активности, соблюдении режима дня, питания, сна, контроля психоэмоциональной активности $[1,8,10]$.

Таблица 7. Показатели состояния регуляторных систем на контрольном этапе педагогического эксперимента в ГС

\begin{tabular}{|c|c|}
\hline \multicolumn{2}{|c|}{ Уровень функционирования } \\
\hline Выраженная тахикардия & 2 \\
\hline \multicolumn{2}{|c|}{ Стабильность регуляции } \\
\hline Нормальная стабильность ритма & 0 \\
\hline \multicolumn{2}{|c|}{ Вегетативный гомеостаз } \\
\hline Умеренное преобладание симпатической нервной системы & 1 \\
\hline \multicolumn{2}{|c|}{ Активность симпатического сосудистого центра } \\
\hline Умеренно повышенная активность сосудистого центра & 1 \\
\hline Степень централизации управления & -2 \\
\hline Резкое снижение активности центральных уровней регуляции & \\
\hline
\end{tabular}

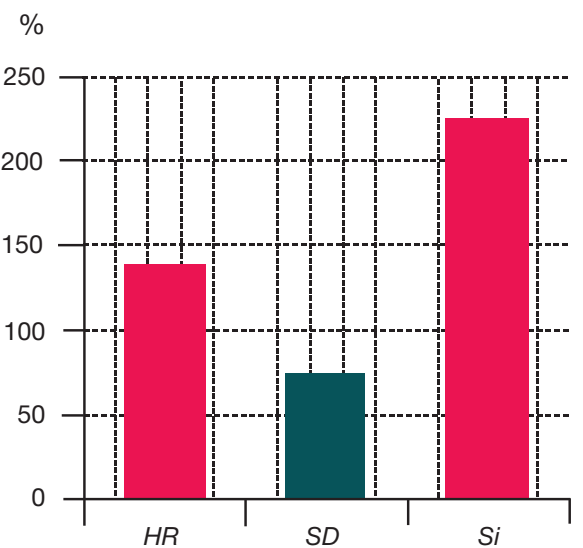

Рис. 2. Основные показатели ритма сердца на контрольном этапе педагогического эксперимента в ГС: HR - частота пульса, уд./мин; SD среднее квадратичное отклонение, мс; $\mathrm{Si}$ - стресс-индекс, усл. ед. 


\section{Индекс нетипичности}

Нормальный уровень

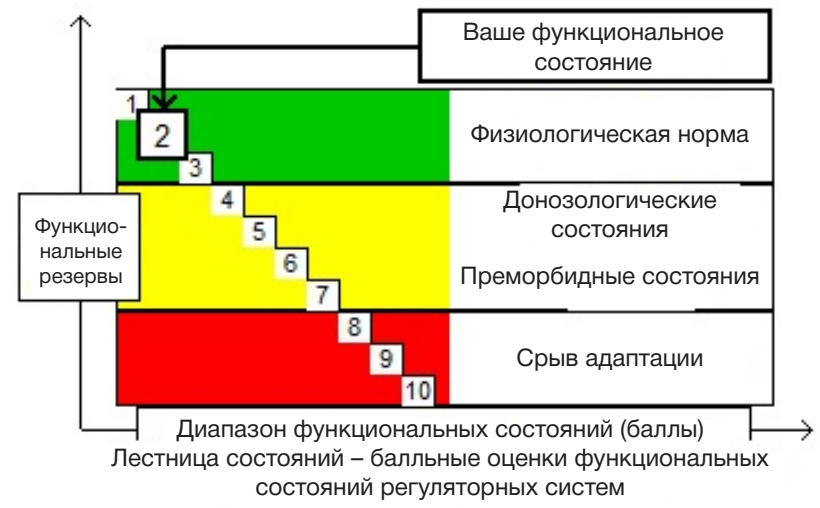

Рис. 3. Диаграмма функционального класса ОГ на контрольном этапе педагогического эксперимента

Повышая умственную и физическую работоспособность ребенка, необходимо учитывать общее состояние его здоровья. Известно, что статичные занятия быстрее утомляют детей, чем динамичные. В связи с этим занятия по ментальному счету должны быть непродолжительными, их необходимо дополнять двигательной и игровой активностью с ПВ, включая игры с мячом, прыжки, упражнения на балансировочной доске, счет с мячом и прыжки через скакалку. Проведенные исследования показали эффективность использования таких упражнений для повышения умственной продуктивности и психомоторных возможностей младших школьников.

\section{ВЫВОДЫ}

Сравнение показателей ВПФ в начале исследования выявило их зависимость от фактора пола в возрасте 7-9 лет. У девочек показатели активности когнитивных

\section{Индекс нетипичности}

Перенапряжение регуляторных механизмов

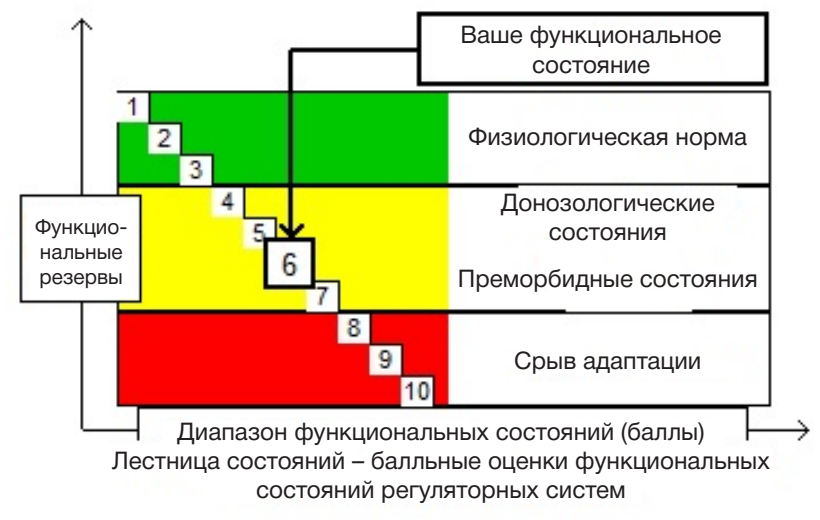

Рис. 4. Диаграмма функционального класса ГС на контрольном этапе педагогического эксперимента

процессов и моторной одаренности на 20-40\% превышали таковые показатели у мальчиков в связи с их опережающим онтогенетическим развитием. У мальчиков 10-12 лет показатели высших психических функций и моторной одаренности имеют выраженный рост на 10-30\% по сравнению с девочками за счет связанной с полом активизацией левой гемисферы.

В ОГ под влиянием занятий ментальной арифметикой с включением ДУ с ПВ выявлено статистически значимое повышение показателей когнитивных процессов, внимания, моторной одаренности, адаптации и стрессоустойчивости, а также оптимизация функций регуляторных систем организма. В ГС ментальные занятия без сопровождения физическими нагрузками не привели к выраженной положительной динамике когнитивных процессов и функциональных систем организма. Результаты исследования позволяют рекомендовать включение ДУ с ПВ в программу обучения ментальному счету.

\section{Литература}

1. Криволапчук И. А., Герасимова А. А., Чернова М. Б., Мышьяков В. В. Исходный вегетативный тонус у детей в начальный период адаптации к образовательной среде. Новые исследования. 2017; 2 (51): 12-21.

2. Криволапчук И. А., Зайцева Г. А, Криволапчук И. И., Буслаков А. П., Носова Р. М., Бондарева С. А. Стрессовая реактивность сердечно-сосудистой системы у школьников в период второго детства. Новые исследования. 2014; 3 (40): 20-30.

3. Ситдиков Ф. Г., Самигулин Г. Х. Возрастные особенности недельной динамики функционального состояния организма младших школьников. Физиология человека. 2000; 26 (6): 167-9.

4. Потупчик Т. В., Макарова М. В., Прахин Е. И., Эверт Л. С., Бакшаева С. С., Щегрова Н. А. Способ прогноза адаптации к школе с использованием анализа вариабельности сердечного ритма. Мать и дитя в Кузбассе. 2012; (4): 32-6.

5. Выготский Л. С. Психология развития ребенка. М.: Эксмо, 2005.

6. Ситдиков Ф. Г., Исхакова А. Т., Кузнецова Н. О. Влияние физической нагрузки на электролитный и вегетативный баланс детей 7-10 лет. Теория и практика фризической культуры. 2009; (10): 25-7.

7. Догадкина С. Б. Особенности вегетативной регуляции сердечного ритма у детей 8 лет. Новые исследования. 2011; 1 (27): 101-8.

8. Шлык Н. И. Сердечный ритм и тип регуляции у детей, подростков и спортсменов. Ижевск: Удмуртский гос. ун-т, 2009; 5-254.

9. Кузнецова О. В., Сонькин В. Д. Вегетативный тонус в звеньях респираторно-гемодинамической системы у детей младшего школьного возраста. Физиология человека. 2009; 35 (6): 94102.

10. Ситдиков Ф. Г., Шейхелисламова М.В.Горманальный статус и вегетативный тонус у детей 7-15 лет. Казань: ТГГПУ, 2008; 147 c.

11. Розенталь С. Г., Сафина А. И. Сравнительный анализ умственной работоспособности в разных возрастных группах. Учен. зап. Казанского университета. Серия: Естественные науки. 2015; 157 (3): 144-50.

12. Мякотных В. В., Ходасевич Л. С. Возрастная динамика умственной работоспособности при различных режимах двигательной активности. Вопросы курортологии, физиотерапии и лечебной физической культуры. 2012; (3): 39-42.

13. Звягина Н. В., Морозова Л. В. Возрастные особенности умственной работоспособности и внимания у детей и подростков города Архангельска. Новые исследования. 2011; 1 (26): 66-76.

14. Дубровина И. В., Андреева А. Д., Дубровина И. В. и др. Младший школьник: развитие познавательных способностей. М.: Просвещение, 2003. 
15. Псеунок А. А. Физиологическая адаптация детей младшего школьного возраста к новым образовательным моделям обучения. Известия высших учебных заведений. СевероКавказский регион. Серия: Естественные науки. 2005; 1 (129): 65-8.

16. Лурия А. Р., Цветкова Л. С. Нейропсихология и проблемы обучения в общеобразовательной школе. Воронеж: МОДЭК, 1997.

17. Кулагина И. Ю. Младшие школьники: особенности развития. М.: Эксмо, 2009; 169 с.

18. Копосова Т. С., Звягина Н. В., Морозова Л. В. Психофизиологические особенности развития детей младшего школьного возраста. Архангельск: Изд-во Помор. ун-та, 1997; 159 с

19. Ахутина Т. В., Меликян 3. А., Низнайко Н. Н. Особенности внимания у младших школьников по данным компьютерного исследования. Вестник Московского университета. Серия 14: Психология. 1999; (4): 36-48.

20. Выготский Л. С. Психология и учение о локализации высших психических функций. В книге: Е. Д. Хомская, редактор. Хрестоматия по нейропсихологии. М.: Ин-т общегуманитарных исследований; Московский психологосоциальный институт, 2004; 91-7.

21. Головей Л. А., Рыбалко Е. Ф., редакторы. Практикум по возрастной психологии: Учебное пособие. СПб.: Речь, 2005; 688 c.

22. Кулешов Л. В. Психологическое обследование: методическое рекомендации. СПб.: Речь, 2001.

23. Венгер А. Л., Цукерман Г. А. Психологическое обследование младших школьников. М.: ВЛАДОС-ПРЕСС, 2005; 159 с.

24. Семенов Ю. Н., Баевский Р. М. Аппаратно-программный комплекс «Варикард» для оценки функционального состояния организма по результатам математического анализа ритма сердца. Вариабельность сердечного ритма. Ижевск, 1996; 160-2.

25. Вайсвалавечене В. Ю. Структура средств, методов и условий развития двигательных способностей у детей старшего дошкольного возраста 5-7 лет [диссертация]. М., 2015.

\section{References}

1. Krivolapchuk IA, Gerasimova AA, Chernova MB, Myshjakov W. Ishodnyj vegetativnyj tonus u detej $v$ nachal'nyj period adaptacii $k$ obrazovatel'noj srede. Novye issledovanija. 2017; 2 (51): 12-21.

2. Krivolapchuk IA, Zajceva GA, Krivolapchuk II, Buslakov AP Nosova RM, Bondareva SA. Stressovaja reaktivnost' serdechnososudistoj sistemy u shkol'nikov v period vtorogo detstva. Novye issledovanija. 2014; 3 (40): 20-30.

3. Sitdikov FG, Samigulin GH. Vozrastnye osobennosti nedel'noj dinamiki funkcional'nogo sostojanija organizma mladshih shkol'nikov. Fiziologija cheloveka. 2000; 26 (6): 167-9.

4. Potupchik TV, Makarova MV, Prahin El, Jevert LS, Bakshaeva SS, Shhegrova NA. Sposob prognoza adaptacii k shkole s ispol'zovaniem analiza variabel'nosti serdechnogo ritma. Mat' i ditja v Kuzbasse. 2012; (4): 32-6.

5. Vygotskij LS. Psihologija razvitija rebenka. M.: Jeksmo, 2005.

6. Sitdikov FG, Ishakova AT, Kuznecova NO. Vlijanie fizicheskoj nagruzki na jelektrolitnyj i vegetativnyj balans detej 7-10 let. Teorija i praktika fizicheskoj kul'tury. 2009; (10): 25-7.

7. Dogadkina SB. Osobennosti vegetativnoj reguljacii serdechnogo ritma u detej 8 let. Novye issledovanija. 2011; 1 (27): 101-8.

8. Shlyk NI. Serdechnyj ritm i tip reguljacii u detej, podrostkov sportsmenov. Izhevsk: Udmurtskij gos. un-t, 2009; 5-254.

9. Kuznecova OV, Sonkin VD. Vegetativnyj tonus $\vee$ zven'jah respiratorno-gemodinamicheskoj sistemy $u$ detej mladshego shkol'nogo vozrasta. Fiziologija cheloveka. 2009; 35 (6): 94-102.

10. Sitdikov FG, Shejhelislamova MV. Gormanal'nyj status vegetativnyj tonus u detej 7-15 let. Kazan': TGGPU, 2008. $147 \mathrm{~s}$

11. Rozental SG, Safina Al. Sravnitel'nyj analiz umstvennoj rabotosposobnosti v raznyh vozrastnyh gruppah. Uchen. zap. Kazanskogo universiteta. Serija: Estestvennye nauki. 2015; 157 (3): 144-50.

12. Mjakotnyh W, Hodasevich LS. Vozrastnaja dinamika umstvennoj rabotosposobnosti pri razlichnyh rezhimah dvigatel'noj aktivnosti. Voprosy kurortologii, fizioterapii i lechebnoj fizicheskoj kul'tury. 2012; (3): 39-42.

13. Zvjagina NV, Morozova LV. Vozrastnye osobennosti umstvennoj rabotosposobnosti i vnimanija u detej i podrostkov goroda

Arhangel'ska. Novye issledovanija. 2011: 1 (26): 66-76.

14. Dubrovina IV, Andreeva AD, Dubrovina IV i dr. Mladshij shkol'nik: razvitie poznavatel'nyh sposobnostej. M.: Prosveshhenie, 2003.

15. Pseunok AA. Fiziologicheskaja adaptacija detej mladshego shkol'nogo vozrasta k novym obrazovatel'nym modeljam obuchenija. Izvestija vysshih uchebnyh zavedenij. SeveroKavkazskij region. Serija: Estestvennye nauki. 2005; 1 (129): 65-8.

16. Lurija AR, Cvetkova LS. Nejropsihologija i problemy obuchenija v obshheobrazovatel'noj shkole. Voronezh: MODJeK, 1997.

17. Kulagina IJu. Mladshie shkol'niki: osobennosti razvitija. M.: Jeksmo, 2009; 169 s.

18. Koposova TS, Zvjagina NV, Morozova LV. Psihofiziologicheskie osobennosti razvitija detej mladshego shkol'nogo vozrasta. Arhangel'sk: Izd-vo Pomor. un-ta, 1997; 159 s.

19. Ahutina TV, Melikjan ZA, Niznajko NN. Osobennosti vnimanija u mladshih shkol'nikov po dannym komp'juternogo issledovanija. Vestnik Moskovskogo universiteta. Serija 14: Psihologija. 1999; (4): 36-48.

20. Vygotskij LS. Psihologija i uchenie o lokalizacii vysshih psihicheskih funkcij V knige: ED Homskaja, redaktor. Hrestomatija po nejropsihologii. M.: In-t obshhegumanitarnyh issledovanij; Moskovskij psihologo-social'nyj institut, 2004; 91-7.

21. Golovej LA, Rybalko EF, redaktory. Praktikum po vozrastnoj psihologii: Uchebnoe posobie. SPb.: Rech', 2005; 688 s.

22. Kuleshov LV. Psihologicheskoe obsledovanie: metodicheskoe rekomendacii. SPb.: Rech', 2001.

23. Venger AL, Cukerman GA. Psihologicheskoe obsledovanie mladshih shkol'nikov. M.: VLADOS-PRESS, 2005; $159 \mathrm{~s}$.

24. Semenov JuH, Baevskij RM. Apparatno-programmnyj kompleks «Varikard» dlja ocenki funkcional'nogo sostojanija organizma po rezul'tatam matematicheskogo analiza ritma serdca. Variabel'nost' serdechnogo ritma. Izhevsk, 1996; 160-2.

25. Vajsvalavechene VJu. Struktura sredstv, metodov i uslovij razvitija dvigatel'nyh sposobnostej u detej starshego doshkol'nogo vozrasta 5-7 let [dissertacija]. M., 2015. 